\title{
Postcodes as useful markers of income in 26000 British households
}

\author{
John Danesh, Simon Gault, Jo Semmence, Paul Appleby, Richard Peto
}

\begin{abstract}
Clinical Trial Service
Unit and

Epidemiological

Studies Unit,

University of Oxford

J Danesh

R Peto by the sex or age of the head of household, by the geographical region of residence, or by different income levels. As such details might be relevant to epidemiologists and statisticians who use postcode estimates in population based studies, this report provides supplementary data.
\end{abstract}

The Family Resources

Survey, Department of

Social Security,

London

S Gault

J Semmence

ICRF Cancer

Epidemiology Unit,

Oxford

P Appleby

Correspondence to: Dr J Danesh, CTSU, Radcliffe Infirmary, Oxford OX2 6HE.

Accepted for publication 13 April 1999

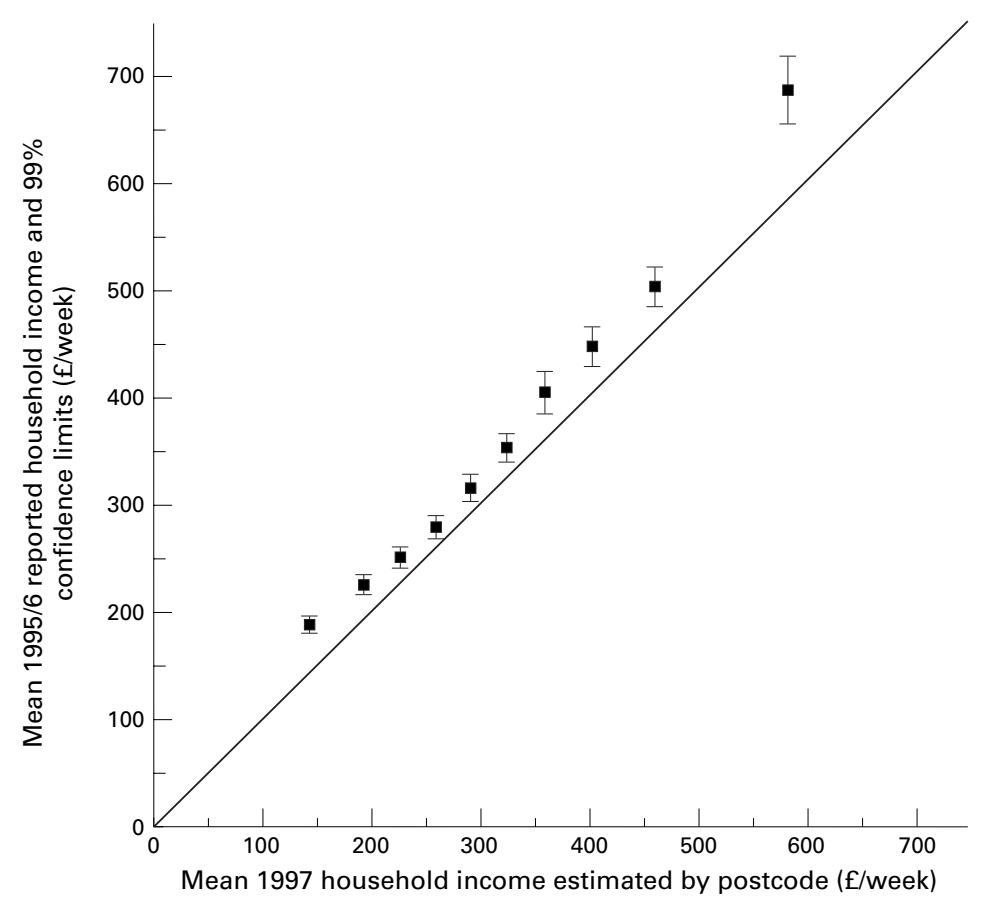

Figure 1 Reported weekly household income by tenths of postcode income estimates.

We previously reported a validation study in 26000 British residents, showing that postcodes were good indicators of a wide range of household characteristics related to socioeconomic status, including occupation, education, home ownership and access to various consumer goods. ${ }^{1}$ That report, however, was too brief to include details of the correlations between postcode estimates and reported household income in potentially relevant subgroups, and therefore it did not describe the data

\section{Methods}

During 1995-6, members of 26445 (70\%) of 37712 private households surveyed in England, Scotland and Wales reported their income (taken as the sum of all sources of reported pretaxation income, apart from the Housing Benefit) to the Family Resources Survey. ${ }^{2}$ During 1985 to 1993 members of 11 million households, or about half of all households in Britain, provided information to a marketing company about annual income and gave their complete (that is, 6 or 7 character) postcode address. This information was used to produce commercial software that estimates household incomes from postcodes after interpolating or smoothing the data in various ways. ${ }^{1}$ We compared household income estimates obtained by this "FIND" software with information reported in the Family Resouces Survey. Matching of the data was carried out at the Office for National Statistics. The investigators in this study were provided with columns of numerical data without any personal identifiers.

\section{Results}

The overall correlation coefficient between postcode estimates and reported values of weekly household income for 26282 people was 0.40 (99\% confidence intervals, 0.39, $0.42 ; 2 \mathrm{p}<0.00001)$. In the 7663 households in which a woman was the head, the correlation coefficient was 0.35 (99\% CI 0.32, 0.37). Each of 11 standard regions had at least 1000 respondents, and the correlation coefficients ranged from $0.32(99 \%$ CI $0.24,0.39)$ for East Anglia to 0.48 (99\% CI $0.45,0.52)$ for the North West region, with generally higher degrees of correlation in northern regions and in areas far from London. There was a lower degree of correlation for respondents older than 70 years $(0.28,99 \%$ CI $0.25,0.31)$. When households were ranked in 10 equal sized groups on the basis of postcode income estimates, there was a definite trend of increasing mean reported income, with a 3.5-fold difference in reported income between the highest and the lowest tenths (fig 1).

\section{Discussion}

This report reinforces and extends our previous observations on the usefulness of postcode estimates as markers of household income in Britain. ${ }^{1}$ Despite slightly lower degrees of correlation for households with female or elderly heads, or for households near London, these results indicate that postcode estimates can be useful proxies of income in a wide range of people. It is not clear, however, why 1997 postcode estimates should consistently tend to underestimate 1995/6 reported incomes (fig 1), although the large discrepancy at the top income level mainly derives from the software's fixed upper estimate. Even so, as the degree of income underestimation was fairly uniform throughout the middle range of income, postcode estimates are not likely to produce material bias when the estimates are used for epidemiological purposes. ${ }^{1}$

Charles Lound of the Office for National Statistics helped with data management, Rom Rahman of QAS Systems provided postcode estimates, and Ian Liddicoat of Market Information is supported by Merton College and a Frohlich award.

1 Danesh J, Semmence J, Gault S, et al. Postcodes as markers of social class in 26,000 British households. BMF 1999;318:843-4.

2 Semmence J, Easto V, Gault S, et al. Family resources survey: Great Britain 1995-96. London: The Stationery Office, 1997. 